University of Zurich

Department of Economics

Working Paper Series

ISSN 1664-7041 (print)

ISSN 1664-705X (online)

Working Paper No. 195

\title{
Contest Success Functions: The Common-Pool Perspective
}

Christian Ewerhart

June 2015 


\title{
Contest Success Functions: The Common-Pool Perspective*
}

\author{
Christian Ewerhart**
}

This version: June 10, 2015

\begin{abstract}
The axiomatic route to the foundation of contest success functions (CSF) has proved to be both useful and prolific. The standard approach in the literature is based on the decision-theoretic notion that choice probabilities should be independent of irrelevant alternatives (Skaperdas, Economic Theory 1996). The present paper develops an alternative approach that suggests itself once the contest is re-interpreted as a common-pool resource problem. Proceeding along these lines, new axiomatizations are obtained for a variety of popular classes of CSFs, including the logit, Tullock, and difference-form CSFs. The axiomatizations provided are particularly parsimonious in the important special case of two contestants.
\end{abstract}

Keywords. Contest success functions; Axiomatic approach; Common-pool resource problems.

JEL-Codes. D24; D42; D62; D72; Q2

*) For useful discussions, I would like to thank Pavlo Blavatskyy and Luis Corchón.

**) University of Zurich, Department of Economics; Schönberggasse 1, 8001 Zurich, Switzerland; e-mail: christian.ewerhart@econ.uzh.ch. 


\section{Introduction}

In the theory of conflict, the so-called contest success function (CSF) captures the technology by which a combination of effort levels, one for each party to the conflict, transforms into an assignment of winning probabilities. As it happened, much of the literature has chosen to work with specific functional forms rather than with general technologies. For instance, scholars have used the lottery contest of Tullock (1980), the logit contest of Dixit (1987), and the difference-form contest of Hirshleifer (1989). One way to justify such choices is it to characterize the functional form using a number of axioms. ${ }^{1}$

The axiomatic foundation of CSFs was introduced to the literature through the seminal paper of Skaperdas (1996), who proposed respective sets of axioms for the CSFs of the logit, Tullock, and difference-form classes. ${ }^{2}$ The requirement that is key to these axiomatizations may be summarized intuitively as follows. Suppose that it becomes known that some player $i$ has not won the prize. Then, conditional on this information, the probability that some other player $j$ has won, rather than any third player $k$, does not depend on the effort level that was chosen by the unsuccessful player $i$. This requirement is structurally analogous to an axiom in the theory of probabilistic choice (Luce, 1959), saying that choice probabilities should be independent of irrelevant alternatives. ${ }^{3}$ The thereby outlined decision-theoretic approach has proved to be both useful and prolific. In particular, the approach has

\footnotetext{
${ }^{1}$ Jia et al. (2013) distinguish foundations of four main types: Stochastic, axiomatic, optimally-designed, and micro-founded.

${ }^{2}$ The marketing literature investigated similar issues somewhat earlier, however. See, in particular, Bell et al. (1975) and Barnett (1976).

${ }^{3}$ Luce's requirement corresponds to the consistency and independence axioms in Skaperdas (1996). Clark and Riis (1998) merged these two axioms. A careful discussion of Luce's axiom from the perspective of contest theory can be found in Jia (2010).
} 
been employed to derive axiomatizations of additional classes of CSFs, such as unfair contests (Clark and Riis, 1998), contests with multi-dimensional investments (Rai and Sarin, 2009; Arbatskaya and Mialon, 2010), group contests (Münster, 2009; Cubel and Sanchez-Pages, 2015), contests on networks (Bozbay and Vesperoni, 2014), and contests for multiple prizes (Vesperoni, 2014; Lu and Wang, 2015).

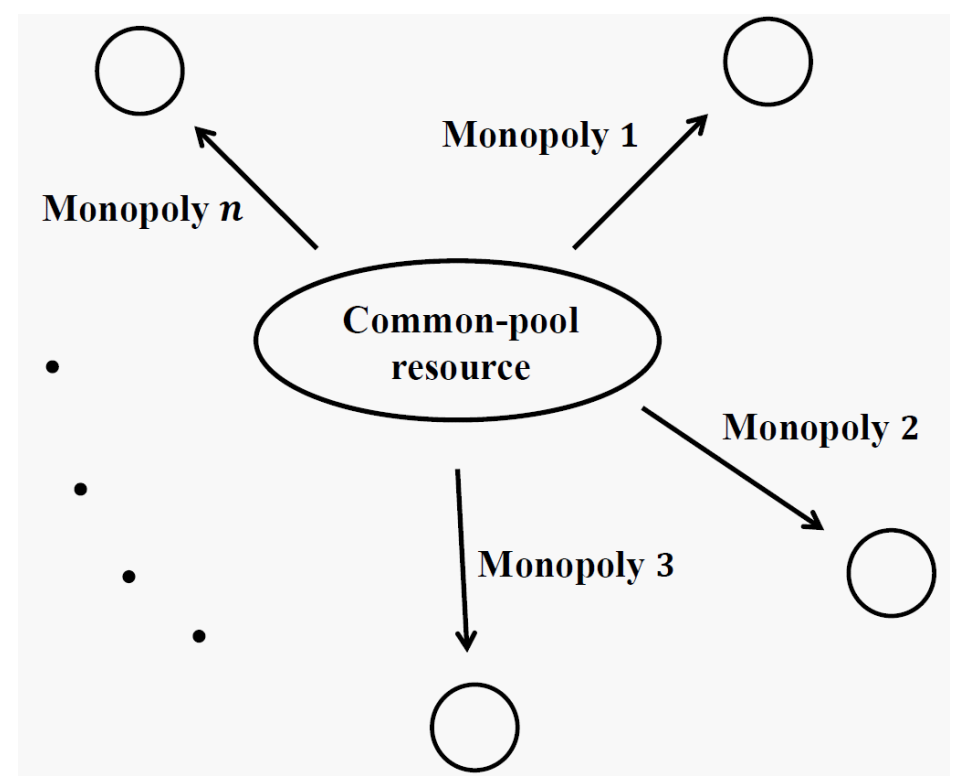

Figure 1. The common-pool interpretation of contests

This paper takes an alternative perspective on the axiomatic foundation of CSFs. Specifically, all what follows draws on the close relationship between rent-seeking contests and common-pool resource problems which was noted especially in the experimental literature (e.g., Walker et al., 1990; Shupp et al., 2013). For illustration, imagine a setting in the tradition of Gordon (1954), where fishermen have unrestrcited access to a common fishing ground. Suppose that individual firms choose their respective fishing effort 
in a non-cooperative fashion, and subsequently sell their catch in separate local markets. Then any fisherman's decision to exert more effort will negatively affect the amount of fish landed by the respective other firms. ${ }^{4}$ This type of setting has been modeled in various ways (e.g., Cornes and Sandler, 1983; Walker et al., 2000; Johnson and Libecap, 1982; Noussair et al., 2015). Cornes and Sandler, for example, assume that each firm's share of industry output equals its share in private inputs, and that industry output is an increasing and concave function of aggregate input. The functional form of payoffs is, therefore, identical to that of a lottery contest with productive group effort, which is a well-known concept in contest theory. ${ }^{5}$ Thus, certain models of common-pool resource problems may be directly interpreted as lotteries contests.

In the analysis below, we will take precisely the opposite direction, starting from an arbitrary contest, and keeping prizes constant. Consistent with the above literature, the common-pool resource problem will be modeled as a strategic game between a given number of firms that operate as monopolists in independent markets, but that are exposed to negative externalities in production (see Figure 1 for illustration). Using suitable specifications of downstream demand and production functions, we will establish a formal isomorphism between the contest on the one hand and an associated common-pool resource problem on the other. Re-interpreting the contest in

\footnotetext{
${ }^{4}$ Gardner et al. (1990, p. 343) provide the following description of such technological externalities: "For fishing trawlers to operate efficiently, they need to travel over a large domain. Fixed nets operating in the same territory increase the operating costs for both trawlers and fixed net users. Similarly, if one group of fishers uses dynamite in their fishing efforts, the costs for other fishers rise as a result of this production technology."

${ }^{5}$ See, e.g., Chung (1996).
} 
this way, properties of CSFs translate into properties of technologies, which may therefore be used to derive production-theoretic characterizations of specific classes of CSF. Following this line of reasoning, new axiomatizations will be obtained for a variety of popular classes of CSFs, including the logit, Tullock, and difference-form contests. ${ }^{6}$

The literature has developed numerous alternative interpretations of the rent-seeking game (see Jia et al., 2013). Restricting attention to the field of industrial economics, there are static and dynamic interpretations. Static interpretations relate to Cournot competition (Szidarovszky and Okuguchi, 1997), and oligopsonistic markets for influence (Menezes and Quiggin, 2010). Dynamic interpretations have been offered in terms of R\&D races (Hirshleifer and Riley, 1992; Jia 2008), and innovation tournaments and patent races (Baye and Hoppe, 2003). The characterization provided below, however, differs from all those contributions by stressing a true monopoly role for all the contestants.

The remainder of the paper is structured as follows. Section 2 introduces the set-up. Logit contests are characterized in Section 3. Section 4 offers some discussion. Tullock contest are considered in Section 4. Section 5 deals with contests of the difference form. Section 6 concludes. Complementary materials and proofs have been relegated to an Appendix.

\footnotetext{
${ }^{6}$ An alternative way to look at the present paper is it to stress the distinction between a variable and a fixed number of contestants. For example, in the axiomatic theory of bargaining, it was initially assumed that the number of agents is fixed, and the extension to a variable number of agents was achieved only subsequently (Thomson, 1985). In the axiomatic foundation of CSF, however, the bulk of the literature has traditionally assumed a variable number of contestants. Only a limited number of papers, including the present one, have worked under the assumption of a fixed number of contestants. I am grateful for Luis Corchón for suggesting the analogy to the literature on axiomatic bargaining.
} 


\section{Contestants as monopolists exploiting a common-pool resource}

Let $N=\{1,2, \ldots, n\}$ be the set of players, where $n \geq 2$. The number of players $n$ will be kept fixed in the sequel.

In an $n$-player rent-seeking contest, each player $i \in N$ chooses a level of effort $X_{i} \geq 0$, with the intention to increase her chances of appropriating a rent which she values with $V_{i}>0$. A $C S F p=\left\{p_{i}\right\}_{i \in N}$ will be understood to be a finite collection of real-valued mappings $p_{i}$ on $\mathbb{R}_{+}^{n} \cdot{ }^{7}$ Structural assumptions on the CSF will be imposed below. We will make use of the usual notational conventions of game theory. In particular, for any given vector of effort levels $\left(X_{1}, \ldots, X_{n}\right) \in \mathbb{R}_{+}^{n}$, we will alternatively write $\left(X_{i} ; X_{-i}\right) \equiv\left(X_{1}, \ldots, X_{n}\right)$, where $X_{-i}=\left(X_{1}, \ldots, X_{i-1}, X_{i+1}, \ldots, X_{n}\right)$. Contestant $i$ 's expected payoff is then given as

$$
\Pi_{i}\left(X_{i} ; X_{-i}\right)=p_{i}\left(X_{i} ; X_{-i}\right) V_{i}-X_{i}
$$

as usual.

In an $n$-player common-pool resource problem, each firm $i=1, \ldots, n$ operates as a monopolist in a separate downstream market, where inverse demand in market $i$ is given by a downward-sloping function $P_{i}=P_{i}\left(Q_{i}\right)$, and $Q_{i}$ denotes firm $i$ 's level of output in the considered period. For example, fish is sold at different shores of the same lake. Interaction among firms is assumed to be either one-shot or time-independent repeated. ${ }^{8}$ Firm $i$ 's stationary

\footnotetext{
${ }^{7}$ As usual, $\mathbb{R}_{+}$and $\mathbb{R}_{++}$denote the respective sets of nonnegative and positive real numbers, and $\mathbb{R}_{+}^{n}$ and $\mathbb{R}_{++}^{n}$ the corresponding $n$-fold Cartesian products.

${ }^{8}$ This is an adequate representation of a common-pool resource problem when the natural replacement rate of the resource is at least as great as current and foreseeable withdrawal rates, so that the common pool is able to maintain itself. Cf. Gardner et al. (1990, p. 346). Also, the literature has remained skeptical about the Folk theorem as a practical policy solution for common-pool resource problems, e.g., because of coordination problems (Ostrom et al., 1994, p. 18). With these considerations in mind, the time-
} 
level of output (or fish landed) $Q_{i}$ is then assumed to be determined by a deterministic production function $Q_{i}=f_{i}\left(X_{i} ; X_{-i}\right)$, where $X_{i} \geq 0$ is the stationary amount of input (or fishing effort). The fact that $Q_{i}$ depends not only on $X_{i}$, as it would in a stand-alone monopoly setting, but also on $X_{-i}$, reflects the technological externalities that cause the resource conflict. Given input choices $X_{i}$ for firm $i$ and a vector of input choices $X_{-i}$ for the other $(n-1)$ monopolists, firm $i$ 's per-period profit is assumed to be given by

$$
\widehat{\Pi}_{i}\left(X_{i} ; X_{-i}\right)=P_{i}\left(f_{i}\left(X_{i} ; X_{-i}\right)\right) f_{i}\left(X_{i} ; X_{-i}\right)-C_{i}\left(X_{i}\right),
$$

where $C_{i}$ is the cost function, and the right-hand-side is interpreted as $\lim _{Q_{i} \rightarrow \infty} P_{i}\left(Q_{i}\right) Q_{i}-C_{i}\left(X_{i}\right)$ if output exceeds all bounds.

Note that costs are considered here as a function of fishing effort, rather than of the weight of landed fish. Letting firms choose inputs is consistent with much of the existing work in the area (e.g., Johnson and Libecap, 1982; Cornes and Sandler, 1983; Walker et al., 1990; Casari and Plott, 2003; Noussair et al., 2015). In fact, allowing firms to choose inputs rather than outputs might be somewhat more natural in a set-up with negative externalities in production. Notwithstanding, in reduced-form models of common-pool resource problems (e.g., Walker et al., 2000), it is assumed that firms choose outputs. As we show in Appendix A, those models may likewise be seen as special cases of the specification (2), once payoffs are expressed in terms of inputs.

The starting point of our analysis is now the following intuitive result.

Observation 1. For any given n-player rent-seeking contest, there exist independent repeated game will be considered here as a stationary repetition of the oneshot game. 
specifications of inverse demand functions $\left\{P_{i}\left(Q_{i}\right)\right\}_{i \in N}$, production functions $\left\{f_{i}\left(X_{i} ; X_{-i}\right)\right\}_{i \in N}$, and cost functions $\left\{C_{i}\left(X_{i}\right)\right\}_{i \in N}$ such that the contest and the resulting common-pool resource problem are strategically equivalent, i.e., such that $\widehat{\Pi}_{i}\left(X_{i} ; X_{-i}\right)=\Pi_{i}\left(X_{i} ; X_{-i}\right)$ for any $i=1, \ldots, n$, and for any vector $\left(X_{i} ; X_{-i}\right) \in \mathbb{R}_{+}^{n}$.

Proof. To a given rent-seeking contest, we associate the common-pool resource problem defined through the primitives

$$
\begin{aligned}
P_{i}\left(Q_{i}\right) & =\frac{V_{i}}{1+Q_{i}}, \\
f_{i}\left(X_{i} ; X_{-i}\right) & =\frac{p_{i}\left(X_{i} ; X_{-i}\right)}{1-p_{i}\left(X_{i} ; X_{-i}\right)}, \\
C_{i}\left(X_{i}\right) & =X_{i} .
\end{aligned}
$$

Fix some firm $i \in N$, and a vector of efforts $\left(X_{i} ; X_{-i}\right) \in \mathbb{R}_{+}^{n}$. Then, provided that $p_{i}\left(X_{i} ; X_{-i}\right)<1$, firm $i$ 's output $Q_{i}=f_{i}\left(X_{i} ; X_{-i}\right)$ is finite, and its revenue may be written as

$$
\begin{aligned}
P_{i}\left(Q_{i}\right) Q_{i} & =P_{i}\left(f_{i}\left(X_{i} ; X_{-i}\right)\right) f_{i}\left(X_{i} ; X_{-i}\right) \\
& =\frac{V_{i}}{1+f_{i}\left(X_{i} ; X_{-i}\right)} f_{i}\left(X_{i} ; X_{-i}\right) \\
& =\frac{V_{i}}{1+\frac{p_{i}\left(X_{i} ; X_{-i}\right)}{1-p_{i}\left(X_{i} ; X_{-i}\right)}} \frac{p_{i}\left(X_{i} ; X_{-i}\right)}{1-p_{i}\left(X_{i} ; X_{-i}\right)} \\
& =V_{i} p_{i}\left(X_{i} ; X_{-i}\right) .
\end{aligned}
$$

Moreover, in limit cases where $p_{i}\left(X_{i} ; X_{-i}\right)=1$, firm $i$ 's revenue satisfies

$$
\lim _{Q_{i} \rightarrow \infty} P_{i}\left(Q_{i}\right) Q_{i}=\lim _{Q_{i} \rightarrow \infty} \frac{V_{i}}{1+Q_{i}} Q_{i}=\lim _{Q_{i} \rightarrow \infty} \frac{Q_{i}}{1+Q_{i}} V_{i}=V_{i}
$$

Thus, either way, $\widehat{\Pi}_{i}\left(X_{i} ; X_{-i}\right)=\Pi_{i}\left(X_{i} ; X_{-i}\right)$. This proves the claim. 


\section{Logit contests}

The re-interpretation of the rent-seeking model achieved in the previous section serves as a basis for deriving alternative axiomatic characterizations of several popular classes of CSFs. In this section, we start with CSFs of the logit class. We will say that $p=\left\{p_{i}\right\}_{i \in N}$ is of the logit form if there is a differentiable and monotone increasing function $g: \mathbb{R}_{+} \rightarrow \mathbb{R}_{+}$such that $g\left(X_{i}\right)>0$ for any $X_{i}>0$, and such that

$$
p_{i}\left(X_{i} ; X_{-i}\right)=\frac{g\left(X_{i}\right)}{g\left(X_{1}\right)+\ldots+g\left(X_{n}\right)}
$$

for all $i=1, \ldots, n$, and for all $\left(X_{i} ; X_{-i}\right) \in \mathbb{R}_{+}^{n} \backslash\{0\} .{ }^{9}$ The function $g$ will be referred to as the impact function.

The common-pool production function (4) associated with the logit CSF is easily calculated to be

$$
\begin{aligned}
f_{i}\left(X_{i} ; X_{-i}\right) & =\frac{p_{i}\left(X_{i} ; X_{-i}\right)}{1-p_{i}\left(X_{i} ; X_{-i}\right)} \\
& =\frac{\frac{g\left(X_{i}\right)}{g\left(X_{1}\right)+\ldots+g\left(X_{n}\right)}}{1-\frac{g\left(X_{i}\right)}{g\left(X_{1}\right)+\ldots+g\left(X_{n}\right)}} \\
& =\frac{\frac{g\left(X_{i}\right)}{g\left(X_{1}\right)+\ldots+g\left(X_{n}\right)}}{g\left(X_{1}\right)+\ldots+g\left(X_{n}\right)} \\
& =\frac{g\left(X_{i}\right)}{g\left(X_{1}\right)+\ldots+g\left(X_{i-1}\right)+g\left(X_{i+1}\right)+\ldots+g\left(X_{n}\right)} .
\end{aligned}
$$

Thus, contestant $i$ 's output is a separable function of $X_{i}$ and $X_{-i}$. In other words, while the respective activity levels of firm $i$ 's opponents may impair firm i's absolute level of output, relative changes to output caused by changes

\footnotetext{
${ }^{9}$ In particular, no restriction on the value of $p_{i}\left(X_{i} ; X_{-i}\right)$ is imposed at $\left(X_{i} ; X_{-i}\right)=0$.
} 
to own input do not depend on other firms' levels of input. Thus, the logit assumption has structural implications for firm $i$ 's scale elasticity, which is defined as usual (e.g., Ewerhart, 2003) as the elasticity of output with respect to own input,

$$
\eta_{i}\left(X_{i} ; X_{-i}\right)=\frac{X_{i}}{f_{i}\left(X_{i} ; X_{-i}\right)} \frac{\partial f_{i}\left(X_{i} ; X_{-i}\right)}{\partial X_{i}} .
$$

Indeed, the vector $X_{-i}$ has the nature of a public bad, and therefore does not change when firm $i$ expands its operations. ${ }^{10}$ For expositional reasons, we will assume throughout that $\eta_{i}$ is well-defined and finite on $\mathbb{R}_{++}^{n}$. This assumption could be easily relaxed. For instance, under the basic axioms (A0) and (A1) introduced below, it would suffice to assume that $p_{i}$ is differentiable on $\mathbb{R}_{++}^{n}$.

The discussion above leads to the following result.

Lemma 1. Suppose that $p$ is of the logit form. Then, in the associated common-pool resource problem, any firm $i$ 's scale elasticity $\eta_{i}\left(X_{i} ; X_{-i}\right)$ at any given input level $X_{i}$ does not depend on the vector of input levels $X_{-i}$ of the respective other firms.

Proof. See the Appendix.

The simple property of the CSF captured by Lemma 1 may be used as a substitute for Luce's axiom to obtain a modified characterization of the CSF of the logit type. To see this, consider the following axioms that may be imposed on an arbitrary $\operatorname{CSF} p=\left\{p_{i}\right\}_{i \in N}$, with $n \geq 2$ fixed.

Axiom A0 (Probability) $\sum_{i \in N} p_{i}\left(X_{1}, \ldots, X_{n}\right)=1$ for any $\left(X_{1}, \ldots, X_{n}\right) \in \mathbb{R}_{+}^{n}$; moreover, $p_{i}\left(X_{1}, \ldots, X_{n}\right) \geq 0$ for all $i \in N$ and any $\left(X_{1}, \ldots, X_{n}\right) \in \mathbb{R}_{+}^{n}$.

\footnotetext{
${ }^{10}$ For careful discussions of this point, see Starrett (1977) or Manning and McMillan (1979)
} 
Axiom A1 (Monotonicity) $p_{i}$ is weakly increasing in $X_{i}$ on $\mathbb{R}_{+}^{n} \backslash\{0\}$, for all $i \in N$; moreover, $X_{i}>0$ implies $p_{i}>0$, for all $i \in N$.

Axiom A2 (Continuity) $p_{i}$ is continuous on $\mathbb{R}_{+}^{n} \backslash\{0\}$, for all $i \in N$.

Axiom A3 (Anonymity) For any permutation $\pi$ of $N$, and for any $\left(X_{1}, \ldots, X_{n}\right) \in$ $\mathbb{R}_{+}^{n}$, we have

$$
p_{i}\left(X_{1}, \ldots, X_{n}\right)=p_{\pi(i)}\left(X_{\pi(1)}, \ldots, X_{\pi(n)}\right)
$$

for all $i \in N$.

Axiom $\mathbf{A} 4$ (Scale elasticity) $\eta_{i}\left(X_{i} ; X_{-i}\right)$ does not depend on $X_{-i}$, for all $i \in N$, and all $X_{i} \in \mathbb{R}_{++}$.

The first four of these axioms do not need much comment. (A0) says that $p$ specifies a distribution of winning probabilities for each vector of efforts. (A1) is a minimalistic monotonicity property. (A2) requires $p$ to be continuous everywhere except at the origin. ${ }^{11}$ (A3) captures the anonymity or fairness of the contest. These four axioms will be employed in all characterizations provided below. The new axiom (A4) ensures that any firm's scale elasticity at any given level of input does not depend on the input levels chosen by the respective other firms.

The following is the main result of the present paper.

Theorem 1. (AO)-(A4) are satisfied if and only if $p$ is of the logit form.

Proof. See the Appendix.

\footnotetext{
${ }^{11}$ For a helpful discussion of the discontinuity of commonly employed CSFs at the origin, see Corchón (2000).
} 


\section{Discussion}

Theorem 1 allows replacing the two axioms employed by Skaperdas (1996) to capture Luce's requirement, i.e., consistency and independence, by the simple requirement that any firm's scale elasticity should be independent of the activity levels chosen by other firms. Thus, the axiomatization provided in the previous section offers a complementary view on the popular logit assumption.

While Theorem 1 delivers a particularly parsimonious axiomatization for the case $n=2$, it holds also for more than two firms. This may be surprising because axiom (A4) imposes very little structure on the way in which the externalities caused by $n-1$ competitors affect the production of any given firm. For example, individual externalities might be substitutes or complements to each other. Intuitively, the crucial element behind the extension to more than two players is axiom (A3). Indeed, anonymity is exploited in the proof using a new type of induction argument, counting down the number of firms that employ an identical level of activity. ${ }^{12}$

Blavatskyy (2010) has recently constructed an example of a CSF that satisfies the relevant set of axioms in Skaperdas (1996) without being of the logit class. Intuitively, that example captures the point that, if there are only two contestants, then there is no additional contestant whose decision could possibly become irrelevant, and hence, in that case, Luce's axiom has

\footnotetext{
${ }^{12}$ Barnett (1976) offers an axiomatic characterization of the asymmetric $n$-player logit CSF, provided that $n \geq 3$. In a nutshell, he assumes the existence of a mathematical function $h_{i}\left(X_{i}\right)$ for each player $i=1, \ldots, n$ such that the absolute value of the marginal rate of substitution of $p_{i}$ with respect to $X_{j}$ and $X_{k}$ equals the ratio between $h_{j}$ and $h_{k}$, for any $j, k \neq i$. Under this condition, player $i$ 's impact function turns out to be the antiderivative of $h_{i}$. Even though Barnett refers to $h_{i}$ as an "elasticity," the approach used in the present paper is clearly different.
} 
too little bite to shape the functional form of the CSF. Only when a third contestant is added, and the axioms are imposed also on the larger contest, the axiomatization is effective. ${ }^{13}$ The problem may be resolved by considering CSF with a positive probability of a draw. Our solution, however, does not change the class of CSF. Indeed, as shown below, the axiomatization captured by Theorem 1 is immune to Blavatskyy's counterexample.

Example 1. Let

$$
p_{1}\left(X_{1}, X_{2}\right)=\frac{\exp \left(\frac{X_{1}}{X_{2}+1}\right)}{\exp \left(\frac{X_{1}}{X_{2}+1}\right)+\exp \left(\frac{X_{2}}{X_{1}+1}\right)} .
$$

As shown in the Appendix, in this case

$$
\eta_{1}\left(X_{1}, X_{2}\right)=X_{1} \cdot\left\{\frac{1}{X_{2}+1}+\frac{X_{2}}{\left(X_{1}+1\right)^{2}}\right\}
$$

In particular, $\eta_{1}(1,1)=\frac{3}{4} \neq \frac{5}{6}=\eta_{1}(1,2)$, and therefore, axiom (A4) does not hold.

\section{The Tullock contest}

For a parameter $R \geq 0$, consider the Tullock CSF $p^{R}=\left\{p_{i}^{R}\right\}_{i \in N}$ by

$$
p_{i}^{R}\left(X_{i} ; X_{-i}\right)=\frac{X_{i}^{R}}{X_{1}^{R}+. .+X_{n}^{R}}
$$

where the ratio is to be read as $1 / n$ when the denominator vanishes. ${ }^{14}$ Obviously, $p^{R}$ is of the logit form, where the impact function is given by

\footnotetext{
${ }^{13}$ For an illustration of this point, see Appendix B.

${ }^{14}$ The properties of the symmetric Nash equilibrium of the Tullock contest are fairly well-understood. See, e.g., Pérez-Castrillo and Verdier (1992), Baye et al. (1994), and Ewerhart (2014).
} 
$g\left(X_{i}\right)=X_{i}^{R}$ for $R>0$, and by $g\left(X_{i}\right)=1$ for $R=0$. In particular, as shown above in (12)-(15), the monopoly output associated with the Tullock CSF is given by

$$
\begin{aligned}
f_{i}\left(X_{i} ; X_{-i}\right) & =\frac{g\left(X_{i}\right)}{g\left(X_{1}\right)+\ldots+g\left(X_{i-1}\right)+g\left(X_{i+1}\right)+\ldots+g\left(X_{n}\right)} \\
& =\frac{X_{i}^{R}}{X_{1}^{R}+\ldots+X_{i-1}^{R}+X_{i+1}^{R}+\ldots+X_{n}^{R}},
\end{aligned}
$$

and the corresponding scale elasticity reads (cf. the proof of Lemma 1)

$$
\begin{aligned}
\eta_{i}\left(X_{i} ; X_{-i}\right) & =\frac{X_{i}}{g\left(X_{i}\right)} \frac{\partial g\left(X_{i}\right)}{\partial X_{i}} \\
& =\frac{R X_{i}^{R-1} X_{i}}{X_{i}^{R}} \\
& =R .
\end{aligned}
$$

The formal discussion may be summarized as follows.

Lemma 2. In the common-pool resource problem associated with the Tullock contest, any given firm's scale elasticity is independent both of its own effort level and of the effort levels chosen by the other firms.

Proof. See text above.

A weak form of this property suffices to pin down the corresponding CSF.

Axiom A4' For any $i \in N$, there exists a constant $R_{i} \geq 0$ such that $\eta_{i}\left(X_{i} ; X_{-i}\right)=R_{i}$ for any $\left(X_{i} ; X_{-i}\right) \in \mathbb{R}_{++}^{n}$.

Replacing (A4) by the more stringent (A4'), we arrive at the following characterization. 
Theorem 2. (AO)-(A3) and (A4') are satisfied if and only if $p=p^{R}$ for some $R \geq 0$.

Proof. See the Appendix.

Kooreman and Schoonbeek (1997) characterize the two-player Tullock CSF. They require that the own-bid elasticity of player 1's winning probability is proportional to player 1's probability of losing, i.e., that

$$
\frac{X_{1}}{p_{1}\left(X_{1}, X_{2}\right)} \frac{\partial p_{1}\left(X_{1}, X_{2}\right)}{\partial X_{1}}=R_{1} \cdot\left(1-p_{1}\left(X_{1}, X_{2}\right)\right)
$$

for some constant $R_{1}>0$. One can show that condition (26) is mathematically equivalent to the corresponding condition imposed by (A4') on $\eta_{1} \cdot{ }^{15}$ In this sense, therefore, Theorem 2 might be seen as an extension of Kooreman and Schoonbeek's result to $n$-player Tullock contests. ${ }^{16}$

\footnotetext{
${ }^{15}$ The proof runs as follows. Note that axiom (A4'), in combination with equations (4) and (16), implies

$$
\begin{aligned}
R_{1} & =\frac{X_{1}}{f_{1}\left(X_{1}, X_{2}\right)} \frac{\partial f_{1}\left(X_{1}, X_{2}\right)}{\partial X_{1}} \\
& =\frac{X_{1}\left(1-p_{1}\left(X_{1}, X_{2}\right)\right)}{p_{1}\left(X_{1}, X_{2}\right)} \frac{\partial\left(p_{1}\left(X_{1}, X_{2}\right) /\left(1-p_{1}\left(X_{1}, X_{2}\right)\right)\right)}{\partial X_{1}} \\
& =\frac{\left(1-p_{1}\left(X_{1}, X_{2}\right)\right) X_{1}}{p_{1}\left(X_{1}, X_{2}\right)} \frac{\partial p_{1}\left(X_{1}, X_{2}\right) / \partial X_{1}}{\left(1-p_{1}\left(X_{1}, X_{2}\right)\right)^{2}} \\
& =\frac{X_{1}}{p_{1}\left(X_{1}, X_{2}\right)\left(1-p_{1}\left(X_{1}, X_{2}\right)\right)} \frac{\partial p_{1}\left(X_{1}, X_{2}\right)}{\partial X_{1}}
\end{aligned}
$$

Multiplying through with $\left(1-p_{1}\left(X_{1}, X_{2}\right)\right)$ yields one direction of the claim. The converse follows by reverting the steps of the argument.

${ }^{16}$ Bell et al. (1975) offer a characterization of the lottery CSF. Their axiom set is different, however. For example, they take the variability assumption to its limit in the sense that the axioms for any number of contestants are needed for characterizing even the two-player lottery contest, just as integer denominators of arbitrary size are needed to approximate any given real number by a ratio of integers.
} 


\section{CSFs of the difference form}

Hirshleifer (1989) suggested that success probabilities in a two-player contest should depend on the difference of efforts. Specifically, for some constant $\sigma \geq 0$, player $i$ 's probability of winning may be given by the convenient functional form

$$
p_{i}\left(X_{1}, X_{2}\right)=\frac{1}{1+\exp \left(\sigma\left(X_{2}-X_{1}\right)\right)},
$$

for $i=1,2$, and any $\left(X_{1}, X_{2}\right) \in \mathbb{R}_{+}^{2}$. In straightforward extension (cf. Skaperdas, 1996), an $n$-player $\operatorname{CSF} p=\left\{p_{i}\right\}_{i \in N}$ will be referred to as being of the difference form if there is a $\sigma \geq 0$ such that

$$
p_{i}\left(X_{1}, \ldots, X_{n}\right)=\frac{1}{1+\sum_{j \neq i} \exp \left(\sigma\left(X_{j}-X_{i}\right)\right)},
$$

for any $i=1, \ldots, n$ and any $\left(X_{1}, \ldots, X_{n}\right) \in \mathbb{R}_{+}^{n}$. It is immediate to see that (32) may be transformed into a logit form, provided that the impact function is chosen as $g\left(X_{i}\right)=\exp \left(\sigma X_{i}\right)$.

The following example extends Blavatskyy's arguments to contests of the difference form.

Example 2. For $n=2$, consider the $\operatorname{CSF} p=\left\{p_{i}\right\}_{i \in N}$ given by

$$
\begin{aligned}
& p_{1}\left(X_{1}, X_{2}\right)=\frac{1}{1+\exp \left(2\left(X_{2}-X_{1}\right)^{3}\right)}, \\
& p_{2}\left(X_{1}, X_{2}\right)=\frac{1}{1+\exp \left(2\left(X_{1}-X_{2}\right)^{3}\right)} .
\end{aligned}
$$

In the Appendix, it is shown that this CSF satisfies the relevant axioms of Skaperdas (1996) for $n=2$, even though it is not of the difference form as defined above. 
We offer a modified axiomatization also for CSFs of the difference form. To this end, we will add Skaperdas' (1996) invariance requirement to our axiom system for the logit form.

(A5) (Translation invariance) $p_{i}\left(X_{1}, \ldots, X_{n}\right)=p_{i}\left(X_{1}+c, \ldots, X_{n}+c\right)$ for any $i \in\{1, \ldots, n\}$, any $\left(X_{1}, \ldots, X_{n}\right) \in \mathbb{R}_{+}^{n}$, and any $c>0$.

The modified axiomatization reads now as follows.

Theorem 3. (A0)-(A5) are satisfied if and only if $p$ is of the difference form.

Proof. See the Appendix.

\section{Conclusion}

In this paper, a formal equivalence has been established between rent-seeking games and common-pool resource problems. While potentially interesting in itself, the equivalence was used to relate properties of CSF to concepts of production theory. As a result, new axiomatizations have been derived for a number of popular CSF.

The axiomatizations provided in this paper are particularly parsimonious when there are only two contestants. This aspect of the common-pool approach should be welcomed because numerous applications of contest theory work with two-person contests as a main building block. ${ }^{17}$ Relatedly, as we discussed, the common-pool approach to the axiomatic foundation of CSF

\footnotetext{
${ }^{17}$ Examples include adversary proceedings (Katz, 1988; Wärneryd, 2000), presidential elections (Klumpp and Polborn, 2006), elimination tournaments (Rosen, 1986; Groh et al., 2012), and animal contests (Hardy and Field, 1998), to name a few.
} 
resolves an important issue recently identified by Blavatskyy (2010). However, based upon a novel induction argument, the common-pool perspective delivers concise axiom sets also for contests with more than two players.

The common-pool perspective may be readily implemented for any subclass of the logit CSF defined through an additional axiom (or through a set of additional axioms). We have illustrated this fact in the case of the difference-form contest. Other straightforward examples include, in particular, the class of CSF defined by Chakravarty and Maharaj (2014) through an invariance axiom that convexifies homogeneity and translation invariance, and the class of two-player CSF characterized by Hwang (2012) through the requirement of a constant "elasticity of augmentation."

The formal equivalence between rent-seeking games and common-pool resource problems has some unexpected implications. For example, one of the main insights in the literature on common-pool resource problems is that small-scale solutions may help to mitigate the tendency to overexploit the resource (e.g., Ostrom, 2000). Observation 1 shows that the literature on the alliance-formation puzzle in contest theory (Esteban and Sákovics, 2003; Konrad and Kovenock, 2009) deals with a structurally quite similar problem. 


\section{Appendix A: Common-pool resource problems}

It will be shown that reduced-form models of common-pool resource problems may be subsumed under the more general form used in the body of the paper.

A number of papers (e.g., Walker et al., 2000; Margreiter et al., 2005; Freeman and Anderson, 2013) employ the reduced-form payoff function

$$
\Pi_{i}^{\mathrm{cpr}}\left(Q_{i} ; Q_{-i}\right)=\alpha Q_{i}-\beta Q_{i}^{2}-Q_{i}\left(\gamma+\kappa \sum_{j=1}^{n} Q_{j}\right),
$$

where $\alpha, \beta, \gamma$, and $\kappa$ are positive constants such that $\alpha>\gamma$. Suppose that firms choose inputs $X_{i}$ rather than outputs $Q_{i}$. Then, one may specify

$$
\begin{aligned}
P_{i}\left(Q_{i}\right) & =\alpha-\gamma-\beta Q_{i}, \\
C_{i}\left(X_{i}\right) & =X_{i}, \\
Q_{i} & =f_{i}\left(X_{i}, X_{-i}\right)=\frac{X_{i}}{\sqrt{\kappa \sum_{j=1}^{n} X_{j}}} .
\end{aligned}
$$

Summing (38) over all players leads to

$$
\sum_{i=1}^{n} Q_{i}=\sqrt{\frac{\sum_{i=1}^{n} X_{i}}{\kappa}} .
$$

Plugging this back into (38), we arrive at

$$
X_{i}=\kappa Q_{i}\left(\sum_{j=1}^{n} Q_{j}\right)
$$

Using (36) and (37), it follows that

$$
\begin{aligned}
& P_{i}\left(f_{i}\left(X_{i} ; X_{-i}\right)\right) f_{i}\left(X_{i} ; X_{-i}\right)-C_{i}\left(X_{i}\right) \\
& =\left(\alpha-\gamma-\beta Q_{i}\right) Q_{i}-X_{i} \\
& =\left(\alpha-\gamma-\beta Q_{i}\right) Q_{i}-\kappa Q_{i} \sum_{j=1}^{n} Q_{j} \\
& =\Pi_{i}^{\mathrm{cpr}}\left(Q_{i} ; Q_{-i}\right) .
\end{aligned}
$$


Thus, the payoffs in the common-pool resource problem (35) are indeed a special case of (2).

\section{Appendix B: Using the decision-theoretic approach to characterize}

\section{a contest with a fixed number of players}

Attention will be restricted to the case $n=2$. To characterize a CSF $p=$ $\left\{p_{i}\right\}_{i=1,2}$, of the logit form, given by functions $p_{1}\left(X_{1}, X_{2}\right)$ and $p_{2}\left(X_{1}, X_{2}\right)$, the usual proof invoking Luce's axiom would tend to assume the existence of a CSF $\widetilde{p}=\left\{\widetilde{p}_{i}\right\}_{i=1,2,3}$, given by functions $\widetilde{p}_{1}\left(X_{1}, X_{2}, X_{3}\right), \widetilde{p}_{2}\left(X_{1}, X_{2}, X_{3}\right)$, and $\widetilde{p}_{3}\left(X_{1}, X_{2}, X_{3}\right)$. Moreover, it would be assumed that (i) the relationship

$$
p_{1}\left(X_{1}, X_{2}\right)=\frac{\widetilde{p}_{1}\left(X_{1}, X_{2}, X_{3}\right)}{\widetilde{p}_{1}\left(X_{1}, X_{2}, X_{3}\right)+\widetilde{p}_{2}\left(X_{1}, X_{2}, X_{3}\right)}
$$

holds, that (ii) the ratio

$$
\frac{\widetilde{p}_{1}\left(X_{1}, X_{2}, X_{3}\right)}{\widetilde{p}_{3}\left(X_{1}, X_{2}, X_{3}\right)} \equiv r_{1}\left(X_{1}, X_{3}\right)
$$

is independent of $X_{2}$, and finally, that (iii) the ratio

$$
\frac{\widetilde{p}_{2}\left(X_{1}, X_{2}, X_{3}\right)}{\widetilde{p}_{3}\left(X_{1}, X_{2}, X_{3}\right)} \equiv r_{2}\left(X_{2}, X_{3}\right)
$$

is independent of $X_{1}$. Under these conditions, letting $X_{3}=a>0$ would imply that

$$
p_{1}\left(X_{1}, X_{2}\right)=\frac{\widetilde{p}_{1}\left(X_{1}, X_{2}, a\right)}{\widetilde{p}_{1}\left(X_{1}, X_{2}, a\right)+\widetilde{p}_{2}\left(X_{1}, X_{2}, a\right)}=\frac{r_{1}\left(X_{1}, a\right)}{r_{1}\left(X_{1}, a\right)+r_{2}\left(X_{2}, a\right)},
$$

which shows that $p$ is indeed of the logit class (Skaperdas, 1996). Even though conditions (i)-(iii) make much sense in a setting with a variable number of contestants, it may also be natural to search for a more parsimonious characterization when the number of contestants is fixed. 


\section{Appendix C: Proofs}

Proof of Lemma 1. Firm $i$ 's scale elasticity at the activity level $X_{i}$ is given by

$$
\eta_{i}\left(X_{i} ; X_{-i}\right)=\frac{X_{i}}{f_{i}\left(X_{i} ; X_{-i}\right)} \frac{\partial f_{i}\left(X_{i} ; X_{-i}\right)}{\partial X_{i}} .
$$

For the logit case, however, it was shown in the body of the paper that

$$
f_{i}\left(X_{i} ; X_{-i}\right)=\frac{g\left(X_{i}\right)}{g\left(X_{1}\right)+\ldots+g\left(X_{i-1}\right)+g\left(X_{i+1}\right)+\ldots+g\left(X_{n}\right)} .
$$

Hence, plugging (49) into (48), one immediately obtains

$$
\eta_{i}\left(X_{i} ; X_{-i}\right)=\frac{X_{i}}{g\left(X_{i}\right)} \frac{\partial g\left(X_{i}\right)}{\partial X_{i}}
$$

which obviously does not depend on $X_{-i}$. This proves the lemma.

The following auxiliary result is used in the proof of Theorem 1.

Lemma C.1 For a fixed $n \geq 2$, let $g>0$ and $\varphi>0$ be functions on $\mathbb{R}_{++}$ and $\mathbb{R}_{++}^{n-1}$, respectively, such that

$$
\sum_{i=1}^{n} \frac{g\left(X_{i}\right)}{g\left(X_{i}\right)+\varphi\left(X_{-i}\right)}=1,
$$

for any $\left(X_{1}, \ldots, X_{n}\right) \in \mathbb{R}_{++}^{n}$. Then, $\varphi\left(X_{-i}\right)=\sum_{j \neq i} g\left(X_{j}\right)$, for any $X_{-i} \in$ $\mathbb{R}_{++}^{n-1}$.

Proof. It clearly suffices to show that

$$
\varphi\left(X_{-1}\right)=\sum_{j=2}^{n} g\left(X_{j}\right)
$$

holds for all vectors $X_{-1}=\left(X_{2}, \ldots, X_{n}\right) \in \mathbb{R}_{++}^{n-1}$. Take an arbitrary vector $X_{-1} \in \mathbb{R}_{++}^{n-1}$. Then, there is a maximum index $k \in\{1, \ldots, n-1\}$ such that

$$
X_{2}=X_{3}=\ldots=X_{k+1}
$$


i.e., the first $k$ components of the vector $X_{-1}$ are all equal. The proof of (52) will be achieved by downwards induction on $k$. To establish the basis for the induction argument, assume that $k=n-1$. In that case, all components of $X_{-1}$ are equal, i.e.,

$$
X_{2}=\ldots=X_{n}
$$

Then, choosing $X_{1} \equiv X_{2}$, equation (51) reads

$$
1=n \frac{g\left(X_{1}\right)}{g\left(X_{1}\right)+\varphi\left(X_{1}^{(n-1)}\right)},
$$

where we use the notation

$$
X_{1}^{(n-1)}=(\underbrace{X_{1}, \ldots, X_{1}}_{(n-1) \text {-times }})
$$

Using (55), one finds that

$$
\varphi\left(X_{-1}\right)=\varphi\left(X_{1}^{(n-1)}\right)=(n-1) g\left(X_{1}\right)=\sum_{j=2}^{n} g\left(X_{j}\right),
$$

thereby establishing (52) for $k=n-1$. Next, we will prove the induction step. To this end, assume that (52) has been shown for all vectors with an initial sequence of $k$ equal components, where $k \in\{2, \ldots, n-1\}$. Take now an arbitrary vector $X_{-1}=\left(X_{2}, \ldots, X_{n}\right) \in \mathbb{R}_{++}^{n-1}$ such that

$$
X_{2}=X_{3}=\ldots=X_{k},
$$

i.e., with an initial sequence of merely $k-1$ equal components. Then, letting again $X_{1} \equiv X_{2}$, equation (51) reads

$$
\begin{aligned}
1 & =k \frac{g\left(X_{1}\right)}{g\left(X_{1}\right)+\varphi\left(X_{1}^{(k-1)}, X_{k+1}, \ldots, X_{n}\right)} \\
& +\sum_{i=k+1}^{n} \frac{g\left(X_{i}\right)}{g\left(X_{i}\right)+\varphi\left(X_{1}^{(k)}, X_{k+1}, \ldots, X_{i-1}, X_{i+1}, \ldots, X_{n}\right)}
\end{aligned}
$$


where we use the notation

$$
X_{1}^{(k)}=(\underbrace{X_{1}, \ldots, X_{1}}_{k \text {-times }}) .
$$

Since the vector $\left(X_{1}^{(k)}, X_{k+1}, \ldots, X_{i-1}, X_{i+1}, \ldots, X_{n}\right)$ has an initial sequence of $k$ equal components, the induction hypothesis implies that

$$
\begin{aligned}
& \varphi\left(X_{1}^{(k)}, X_{k+1}, \ldots, X_{i-1}, X_{i+1}, \ldots, X_{n}\right) \\
& =k g\left(X_{1}\right)+g\left(X_{k+1}\right)+\ldots+g\left(X_{i-1}\right)+g\left(X_{i+1}\right)+\ldots g\left(X_{n}\right) .
\end{aligned}
$$

Plugging this into (59), we obtain

$$
\begin{aligned}
1 & =k \frac{g\left(X_{1}\right)}{g\left(X_{1}\right)+\varphi\left(X_{1}^{(k-1)}, X_{k+1}, \ldots, X_{n}\right)} \\
& +\sum_{i=k+1}^{n} \frac{g\left(X_{i}\right)}{g\left(X_{i}\right)+k g\left(X_{1}\right)+g\left(X_{k+1}\right)+\ldots+g\left(X_{i-1}\right)+g\left(X_{i+1}\right)+\ldots g\left(X_{n}\right)} \\
& =k \frac{g\left(X_{1}\right)}{g\left(X_{1}\right)+\varphi\left(X_{1}^{(k-1)}, X_{k+1}, \ldots, X_{n}\right)}+\sum_{i=k+1}^{n} \frac{g\left(X_{i}\right)}{k g\left(X_{1}\right)+\sum_{j=k+1}^{n} g\left(X_{j}\right)}
\end{aligned}
$$

Solving now for $\varphi\left(X_{1}^{(k-1)}, X_{k+1}, \ldots, X_{n}\right)$ yields

$$
\begin{aligned}
& \varphi\left(X_{1}^{(k-1)}, X_{k+1}, \ldots, X_{n}\right) \\
& =\frac{k g\left(X_{1}\right)}{1-\sum_{i=k+1}^{n} \frac{g\left(X_{i}\right)}{k g\left(X_{1}\right)+\sum_{j=k+1}^{n} g\left(X_{j}\right)}-g\left(X_{1}\right)} \\
& =\frac{k g\left(X_{1}\right)\left\{k g\left(X_{1}\right)+\sum_{j=k+1}^{n} g\left(X_{j}\right)\right\}}{k g\left(X_{1}\right)+\sum_{j=k+1}^{n} g\left(X_{j}\right)-\sum_{i=k+1}^{n} g\left(X_{i}\right)}-g\left(X_{1}\right) \\
& =(k-1) g\left(X_{1}\right)+\sum_{j=k+1}^{n} g\left(X_{j}\right) .
\end{aligned}
$$


Hence, relationship (52) holds also for all vectors with an initial sequence of $k-1$ equal components. By downwards induction, starting at $k=n-1$, and ending at $k=2$, we have therefore shown that (52) holds indeed for any vector $X_{-1}=\left(X_{2}, \ldots, X_{n}\right) \in \mathbb{R}_{++}^{n-1}$. This proves the lemma.

Proof of Theorem 1. We prove separately the necessity and sufficiency of the axioms. (Necessity) Suppose that $p$ is of the logit form. Then (A0)(A3) are obviously satisfied. Moreover, (A4) is an immediate consequence of Lemma 1. (Sufficiency) Suppose next that axioms (A0)-(A4) hold, and keep one player $i \in N$ fixed. By (A4), the function

$$
\begin{aligned}
\eta_{i}\left(X_{i} ; X_{-i}\right) & =\frac{X_{i}}{f_{i}\left(X_{i} ; X_{-i}\right)} \frac{\partial f_{i}\left(X_{i} ; X_{-i}\right)}{\partial X_{i}} \\
& =\frac{\partial \ln f_{i}\left(X_{i} ; X_{-i}\right)}{\partial \ln X_{i}}
\end{aligned}
$$

is well-defined and finite for any $\left(X_{i} ; X_{-i}\right) \in \mathbb{R}_{++}^{n}$, and does not depend on $X_{-i}$. The fundamental theorem of analysis implies now that

$$
\begin{aligned}
\ln f_{i}\left(X_{i}^{\prime} ; X_{-i}\right)-\ln f_{i}\left(X_{i}^{\prime \prime} ; X_{-i}\right) & =\int_{\ln X_{i}^{\prime}}^{\ln X_{i}^{\prime \prime}} \eta_{i}\left(X_{i} ; X_{-i}\right) d \ln X_{i} \\
& =\int_{X_{i}^{\prime}}^{X_{i}^{\prime \prime}} \eta_{i}\left(X_{i} ; X_{-i}\right) \frac{d X_{i}}{X_{i}}
\end{aligned}
$$

for any $X_{i}^{\prime \prime} \geq X_{i}^{\prime}>0$, and for any $X_{-i} \in \mathbb{R}_{++}^{n-1}$. Applying the exponential function to both sides of the equation, and setting $X_{i}^{\prime \prime}=1$, we obtain

$$
f_{i}\left(X_{i}^{\prime} ; X_{-i}\right)=\underbrace{f_{i}\left(1 ; X_{-i}\right)}_{\equiv \phi_{i}\left(X_{-i}\right)} \cdot \underbrace{\exp \left\{\int_{X_{i}^{\prime}}^{1} \eta_{i}\left(X_{i} ; X_{-i}\right) \frac{d X_{i}}{X_{i}}\right\}}_{\equiv g_{i}\left(X_{i}^{\prime}\right)} .
$$

Equation (71) continues to hold for $X_{i}^{\prime}>1$, provided the integral is interpreted in the usual way, i.e., via the relationship

$$
\int_{X_{i}^{\prime}}^{1} \eta_{i}\left(X_{i} ; X_{-i}\right) \frac{d X_{i}}{X_{i}}=-\int_{1}^{X_{i}^{\prime}} \eta_{i}\left(X_{i} ; X_{-i}\right) \frac{d X_{i}}{X_{i}}
$$


Thus, there are functions $\phi_{i}>0$ and $g_{i}>0$ such that

$$
f_{i}\left(X_{i} ; X_{-i}\right)=\phi_{i}\left(X_{-i}\right) \cdot g_{i}\left(X_{i}\right)
$$

for any $\left(X_{i} ; X_{-i}\right) \in \mathbb{R}_{++}^{n}$. Moreover, by anonymity, neither $\phi_{i}$ nor $g_{i}$ depend on $i$. Hence, we may drop the index, and obtain

$$
\begin{aligned}
p_{i}\left(X_{i} ; X_{-i}\right) & =\frac{f_{i}\left(X_{i} ; X_{-i}\right)}{1+f_{i}\left(X_{i} ; X_{-i}\right)} \\
& =\frac{\phi\left(X_{-i}\right) g\left(X_{i}\right)}{1+\phi\left(X_{-i}\right) g\left(X_{i}\right)} \\
& =\frac{g\left(X_{i}\right)}{g\left(X_{i}\right)+\frac{1}{\phi\left(X_{-i}\right)}} .
\end{aligned}
$$

for any $\left(X_{i} ; X_{-i}\right) \in \mathbb{R}_{++}^{n}$, and any $i=1, \ldots, n$. Invoking now Lemma C.1, for $\varphi\left(X_{-i}\right)=\frac{1}{\phi\left(X_{-i}\right)}$, it follows that

$$
\frac{1}{\phi\left(X_{-i}\right)}=\sum_{j \neq i} g\left(X_{j}\right)
$$

Hence,

$$
p_{i}\left(X_{i} ; X_{-i}\right)=\frac{g\left(X_{i}\right)}{g\left(X_{i}\right)+\sum_{j \neq i} g\left(X_{j}\right)} .
$$

Moreover, from (A1), $\eta_{i} \geq 0$, so that $g$ is monotone increasing. This proves the theorem.

The following claim has been made in Example 1.

\section{Lemma C.2. For}

$$
p_{1}\left(X_{1}, X_{2}\right)=\frac{\exp \left(\frac{X_{1}}{X_{2}+1}\right)}{\exp \left(\frac{X_{1}}{X_{2}+1}\right)+\exp \left(\frac{X_{2}}{X_{1}+1}\right)},
$$


we have

$$
\eta_{1}\left(X_{1}, X_{2}\right)=X_{1} \cdot\left\{\frac{1}{X_{2}+1}+\frac{X_{2}}{\left(X_{1}+1\right)^{2}}\right\}
$$

Proof. The common-pool resource production function associated with $p_{1}$ is given by

$$
f_{1}\left(X_{1}, X_{2}\right)=\frac{p_{1}\left(X_{1}, X_{2}\right)}{1-p_{1}\left(X_{1}, X_{2}\right)}=\frac{\exp \left(\frac{X_{1}}{X_{2}+1}\right)}{\exp \left(\frac{X_{2}}{X_{1}+1}\right)}=\exp \left(\frac{X_{1}}{X_{2}+1}-\frac{X_{2}}{X_{1}+1}\right) .
$$

Using (67-68), it follows that

$$
\eta_{1}\left(X_{1}, X_{2}\right)=X_{1} \frac{\partial \ln f_{1}\left(X_{1}, X_{2}\right)}{\partial X_{1}}=X_{1} \cdot\left\{\frac{1}{X_{2}+1}+\frac{X_{2}}{\left(X_{1}+1\right)^{2}}\right\} .
$$

This proves the lemma.

Proof of Theorem 2. (Necessity) Axioms (A0)-(A3) are obviously satisfied. (A4') follows from Lemma 2. (Sufficiency) Suppose that (A0)-(A3) and (A4') hold. Since (A4') is more stringent than (A4), Theorem 1 implies that $p$ is of the logit class. Thus, there exists a differentiable and monotone increasing function $g$ on $\mathbb{R}_{+}$such that $g\left(X_{i}\right)>0$ for any $X_{i}>0$, and such that

$$
p_{i}\left(X_{i} ; X_{-i}\right)=\frac{g\left(X_{i}\right)}{g\left(X_{1}\right)+\ldots+g\left(X_{n}\right)}
$$

for all $i=1, \ldots, n$, and for all $\left(X_{i} ; X_{-i}\right) \in \mathbb{R}_{+}^{n} \backslash\{0\}$. By (A4'), there is a finite constant $R_{i}$ such that $\eta_{i}\left(X_{i} ; X_{-i}\right)=R_{i}$ on $\mathbb{R}_{++}^{n}$. Since, as shown in the proof of Lemma 1,

$$
\eta_{i}\left(X_{i} ; X_{-i}\right)=\frac{X_{i}}{g\left(X_{i}\right)} \frac{\partial g\left(X_{i}\right)}{\partial X_{i}}
$$

we find that

$$
\frac{X_{i}}{g\left(X_{i}\right)} \frac{\partial g\left(X_{i}\right)}{\partial X_{i}}=R_{i}
$$


This differential equation has the general solution $g\left(X_{i}\right)=\alpha_{i} X_{i}^{R_{i}}$, where $\alpha_{i} \in \mathbb{R}$. Recall that $g\left(X_{i}\right)>0$ for any $X_{i}>0$. Hence, $\alpha_{i}>0$ for all $i=1, \ldots, n$. Moreover, since the impact function $g$ is homogeneous across contestants, it follows that $\alpha_{1}=\ldots=\alpha_{n} \equiv \alpha$ and $R_{1}=\ldots=R_{n} \equiv R$. Thus,

$$
\begin{aligned}
p_{i}\left(X_{i} ; X_{-i}\right) & =\frac{g\left(X_{i}\right)}{g\left(X_{1}\right)+\ldots+g\left(X_{n}\right)} \\
& =\frac{\alpha X_{i}^{R}}{\alpha X_{1}^{R}+\ldots+\alpha X_{n}^{R}} \\
& =\frac{X_{i}^{R}}{X_{1}^{R}+\ldots+X_{n}^{R}} \\
& =p_{i}^{R}\left(X_{i} ; X_{-i}\right) .
\end{aligned}
$$

This proves the theorem.

The following claim has been made in Example 2.

Lemma C.3. The CSF $p=\left\{p_{i}\right\}_{i=1,2}$ given by

$$
\begin{aligned}
& p_{1}\left(X_{1}, X_{2}\right)=\frac{1}{1+\exp \left(2\left(X_{2}-X_{1}\right)^{3}\right)}, \\
& p_{2}\left(X_{1}, X_{2}\right)=\frac{1}{1+\exp \left(2\left(X_{1}-X_{2}\right)^{3}\right)} .
\end{aligned}
$$

satisfies the conditions of Skaperdas (1996, Theorem 3) for $n=2$, even though it is not of the difference form as defined in Section 6 .

Proof. We first check the various conditions of the theorem. 
Ska96-A1 By straightforward calculation,

$$
\begin{aligned}
& p_{1}\left(X_{1}, X_{2}\right)+p_{2}\left(X_{1}, X_{2}\right) \\
& =\frac{1}{1+\exp \left(2\left(X_{2}-X_{1}\right)^{3}\right)}+\frac{1}{1+\exp \left(2\left(X_{1}-X_{2}\right)^{3}\right)} \\
& =\frac{\exp \left(\left(X_{1}-X_{2}\right)^{3}\right)}{\exp \left(\left(X_{1}-X_{2}\right)^{3}\right)+\exp \left(\left(X_{2}-X_{1}\right)^{3}\right)} \\
& +\frac{\exp \left(\left(X_{2}-X_{1}\right)^{3}\right)}{\exp \left(\left(X_{1}-X_{2}\right)^{3}\right)+\exp \left(\left(X_{2}-X_{1}\right)^{3}\right)} \\
& =1 .
\end{aligned}
$$

Moreover, $p_{1}\left(X_{1}, X_{2}\right) \geq 0, p_{2}\left(X_{1}, X_{2}\right) \geq 0$, for any $X_{1} \geq 0, X_{2} \geq 0$; finally, $p_{1}\left(X_{1}, X_{2}\right)>0$ if $X_{1}>0$, and $p_{2}\left(X_{1}, X_{2}\right)>0$ if $X_{2}>0$.

Ska96-A2 Since the mapping $x \mapsto x^{3}$ is strictly increasing, $p_{1}\left(X_{1}, X_{2}\right)$ is strictly increasing in $X_{1}$, for any $X_{2} \geq 0$, and strictly decreasing in $X_{2}$, for any $X_{1} \geq 0$. Similarly, $p_{2}\left(X_{1}, X_{2}\right)$ is strictly increasing in $X_{2}$, for any $X_{1} \geq 0$, and strictly decreasing in $X_{1}$, for any $X_{2} \geq 0$.

Ska96-A3 Note that

$$
p_{2}\left(X_{2}, X_{1}\right)=\frac{1}{1+\exp \left(2\left(X_{2}-X_{1}\right)^{3}\right)}=p_{1}\left(X_{1}, X_{2}\right)
$$

An analogous argument shows that $p_{1}\left(X_{2}, X_{1}\right)=p_{2}\left(X_{1}, X_{2}\right)$.

Ska96-A4 For $n=2$ contestants, this property requires only that

$$
p_{1}\left(X_{1}, X_{2}\right)=\frac{p_{1}\left(X_{1}, X_{2}\right)}{p_{1}\left(X_{1}, X_{2}\right)+p_{2}\left(X_{2}, X_{1}\right)},
$$

which is trivially satisfied because $p_{1}\left(X_{1}, X_{2}\right)+p_{2}\left(X_{2}, X_{1}\right)=1$, as shown above. 
Ska96-A5 There are only $n=2$ contestants. Therefore, there are no other players whose effort levels $p_{1}\left(X_{1}, X_{2}\right)$ or $p_{2}\left(X_{1}, X_{2}\right)$ could possibly be a function of. Thus, this property holds trivially.

Ska96-A7 For any $c \in \mathbb{R}$ such that $X_{i}+c \geq 0$ for $i=1,2$, we have

$$
\begin{aligned}
p_{1}\left(X_{1}+c, X_{2}+c\right) & =\frac{1}{1+\exp \left(2\left(\left(X_{2}+c\right)-\left(X_{1}+c\right)\right)^{3}\right)} \\
& =\frac{1}{1+\exp \left(2\left(X_{2}-X_{1}\right)^{3}\right)} \\
& =p_{1}\left(X_{1}, X_{2}\right),
\end{aligned}
$$

and, similarly,

$$
p_{2}\left(X_{1}+c, X_{2}+c\right)=p_{2}\left(X_{1}, X_{2}\right)
$$

Thus, all conditions of Skaperdas (1996, Theorem 3) for $n=2$ are satisfied. Next, it is shown that $p$ is not of the difference form. To provoke a contradiction, suppose that there is a $\sigma>0$ such that

$$
\frac{1}{1+\exp \left(\sigma\left(X_{2}-X_{1}\right)\right)}=\frac{1}{1+\exp \left(2\left(X_{2}-X_{1}\right)^{3}\right)}
$$

for any $\left(X_{1}, X_{2}\right) \in \mathbb{R}_{+}^{2}$. Then

$$
\exp \left(\sigma\left(X_{2}-X_{1}\right)\right)=\exp \left(2\left(X_{2}-X_{1}\right)^{3}\right)
$$

Taking the log on both side, and writing $z=X_{2}-X_{1}$, we obtain

$$
\left(2 z^{2}-\sigma\right) z=0
$$

Since the real parameter $z$ may assume more than three different values, this cannot hold for any fixed $\sigma$, and we arrive at the desired contradiction. 
The importance of the following type of result for the characterization of CSF has been noted by Skaperdas (1996).

Lemma C.4 If $\xi \geq 0$ is a continuous function that satisfies $\xi\left(Z_{1}+Z_{2}\right)=$ $\xi\left(Z_{1}\right)+\xi\left(Z_{2}\right)$ for all $Z_{1}>0$ and all $Z_{2}>0$, then there is a $\lambda \geq 0$ such that $\xi(Z)=\lambda Z$ for any $Z>0$.

Proof. See Aczél (1966, p. 34).

The subsequent proof is adapted from Skaperdas (1996).

Proof of Theorem 3. (Necessity) As discussed in Section 6, any CSF of the difference form belongs, in particular, to the logit class. Therefore, (A0)-(A4) follow from Theorem 1 . To prove (A5), let $\left(X_{1}, \ldots, X_{n}\right) \in \mathbb{R}_{+}^{n}$, and $c>0$. Then,

$$
\begin{aligned}
p_{i}\left(X_{1}+c, \ldots, X_{n}+c\right) & =\frac{\exp \left(k\left(X_{i}+c\right)\right)}{\exp \left(k\left(X_{1}+c\right)\right)+\ldots+g\left(k\left(X_{n}+c\right)\right)} \\
& =\frac{\exp \left(k X_{i}\right)}{\exp \left(k X_{1}\right)+\ldots+g\left(k X_{n}\right)} \\
& =p_{i}\left(X_{1}+c, \ldots, X_{n}+c\right),
\end{aligned}
$$

for any $i \in\{1, \ldots, n\}$, which proves the claim. (Sufficiency) Suppose that (A0)-(A5) hold. Then, by Theorem 1, there exists a differentiable and monotone increasing function $g$ on $\mathbb{R}_{+}$such that $g\left(X_{i}\right)>0$ for any $X_{i}>0$, and such that

$$
p_{i}\left(X_{1}, \ldots, X_{n}\right)=\frac{g\left(X_{i}\right)}{g\left(X_{1}\right)+\ldots+g\left(X_{n}\right)},
$$

for all $i=1, \ldots, n$, and for all $\left(X_{1}, \ldots, X_{n}\right) \in \mathbb{R}_{+}^{n} \backslash\{0\}$. From (A5), it follows that

$$
\frac{g\left(X_{i}\right)}{g\left(X_{1}\right)+\ldots+g\left(X_{n}\right)}=\frac{g\left(X_{i}+c\right)}{g\left(X_{1}+c\right)+\ldots+g\left(X_{n}+c\right)}
$$


for any $c>0$, any $i=1, \ldots, n$, and any $\left(X_{1}, \ldots, X_{n}\right) \in \mathbb{R}_{+}^{n} \backslash\{0\}$. Since $n \geq 2$, there exists some player $j \neq i$ such that, likewise

$$
\frac{g\left(X_{j}\right)}{g\left(X_{1}\right)+\ldots+g\left(X_{n}\right)}=\frac{g\left(X_{j}+c\right)}{g\left(X_{1}+c\right)+\ldots+g\left(X_{n}+c\right)} .
$$

Combining (108) and (109) yields

$$
\frac{g\left(X_{j}\right)}{g\left(X_{i}\right)}=\frac{g\left(X_{j}+c\right)}{g\left(X_{i}+c\right)}
$$

provided that $X_{i}>0$. In particular, for $X_{j}=0$,

$$
\frac{g(0)}{g\left(X_{i}\right)}=\frac{g(c)}{g\left(X_{i}+c\right)}
$$

which implies $g(0)>0$ (by evaluating at $c>0$ ). Moreover, applying the log to both sides of equation (111), and re-arranging, we obtain

$$
\ln \left(\frac{g\left(X_{i}\right)}{g(0)}\right)+\ln \left(\frac{g(c)}{g(0)}\right)=\ln \left(\frac{g\left(X_{i}+c\right)}{g(0)}\right),
$$

for any $c>0$ and any $X_{i}>0$. Using the notation

$$
\xi(Z)=\ln \left(\frac{g(Z)}{g(0)}\right)
$$

we have that, for any $Z_{1}>0$ and any $Z_{2}>0$,

$$
\xi\left(Z_{1}\right)+\xi\left(Z_{2}\right)=\xi\left(Z_{1}+Z_{2}\right) .
$$

Since $g$ is differentiable, $\xi$ is continuous on $\mathbb{R}_{++}$. Hence, by Lemma C.4 above, $\xi(Z)=\lambda Z$ for some $\lambda \geq 0$. Thus, $g(Z)=g(0) \exp (\lambda Z)$ for any $Z>0$, and therefore, for any $\left(X_{1}, \ldots, X_{n}\right) \in \mathbb{R}_{+}^{n} \backslash\{0\}$,

$$
\begin{aligned}
p_{i}\left(X_{1}, \ldots, X_{n}\right) & =\frac{g(0) \exp \left(\lambda X_{i}\right)}{g(0) \exp \left(\lambda X_{1}\right)+\ldots+g(0) \exp \left(\lambda X_{n}\right)} \\
& =\frac{\exp \left(\lambda X_{i}\right)}{\exp \left(\lambda X_{1}\right)+\ldots+\exp \left(\lambda X_{n}\right)} .
\end{aligned}
$$


Finally, one notes that from (A3),

$$
p_{i}(0, \ldots, 0)=\frac{1}{n}=\frac{\exp (\lambda \cdot 0)}{\exp (\lambda \cdot 0)+\ldots+\exp (\lambda \cdot 0)} .
$$

It follows that $p=\left\{p_{i}\right\}_{i \in N}$ is indeed of the difference form. 


\section{References}

Aczél, J. (1966), Lectures on Functional Equations and their Applications, Academic Press.

Arbatskaya, M., Mialon, H.M. (2010), Multi-activity contests, Economic Theory 43, 23-43.

Barnett, A.I. (1976), More on a market share theorem, Journal of Marketing Research 13, 104-109.

Baye, M.R., Hoppe, H.C. (2003), The strategic equivalence of rent-seeking, innovation, and patent-race games, Games and Economic Behavior 44, 217226.

Baye, M.R., Kovenock, D., de Vries, C. (1994), The solution to the Tullock rent-seeking game when $R$ is greater than 2: Mixed-strategy equilibria and mean dissipation rates, Public Choice 81, 363-380.

Bell, D.E., Keeney, R.L., Little, J.D. (1975), A market share theorem, Journal of Marketing Research 12, 136-141.

Blavatskyy, P. (2010), Contest success functions with the possibility of a draw: Axiomatization, Journal of Mathematical Economics 46, 267-276.

Bozbay, İ., Vesperoni, A. (2014), A contest success function for networks, mimeo.

Casari, M., Plott, C.R. (2003), Decentralized management of common property resources: Experiments with a centuries-old institution, Journal of Economic Behavior \&S Organization 51, 217-247. 
Chakravarty, S.R., Maharaj, B. (2014), New contest success functions, ECINEQ WP 340.

Chung, T.Y. (1996). Rent-seeking contest when the prize increases with aggregate efforts, Public Choice 87, 55-66.

Clark, D., Riis, C. (1998), Contest success functions: An extension, Economic Theory 11, 201-204.

Corchón, L. (2000), On the allocative effects of rent-seeking, Journal of Public Economic Theory 2, 483-491.

Cubel, M., Sanchez-Pages, S. (2015), An axiomatization of difference-form contest success functions, mimeo.

Cornes, R., Sandler, T. (1983), On commons and tragedies, American Economic Review 73 787-792.

Dixit, A. (1987), Strategic behavior in contests, American Economic Review 5, 891-898.

Esteban, J., Sákovics, J. (2003), Olson vs. Coase: Coalitional worth in conflict, Theory and Decision 55, 339-357.

Ewerhart, C. (2003), A short and intuitive proof of Marshall's Rule, Economic Theory 22, 415-418.

Ewerhart, C. (2014), Mixed equilibria in Tullock contests, Economic Theory, 1-13. DOI 10.1007/s00199-014-0835-x. 
Freeman, M.A., Anderson, C.M. (2013), Modeling effort and lobbying in a heterogeneous common pool resource setting, Environmental and Resource Economics 56, 399-414.

Gardner, R., Ostrom, E., Walker, J.M. (1990), The nature of common-pool resource problems, Rationality and Society 2, 335-358.

Gordon, H.S. (1954), The economic theory of a common-property resource: The fishery, Journal of Political Economy 62, 124-142.

Groh, C., Moldovanu, B., Sela, A., Sunde, U. (2012), Optimal seedings in elimination tournaments, Economic Theory 49, 59-80.

Hardy, I., Field, S. (1998), Logistic analysis of animal contests, Animal Behaviour 56, 787-792.

Hirshleifer, J. (1989), Conflict and rent-seeking success functions: Ratio vs. difference models of relative success, Public Choice 63, 101-112.

Hirshleifer, J., Riley, J.G. (1992), The analytics of uncertainty and information, Cambridge.

Hwang, S.-H. (2012), Technology of military conflict, military spending, and war, Journal of Public Economics 96, 226-236.

Jia, H. (2008), A stochastic derivation of the ratio form of contest success functions, Public Choice 135, 125-130.

Jia, H. (2010), On a class of contest success functions, The B.E. Journal of Theoretical Economics 10, Article 32. 
Jia, H., Skaperdas, S., Vaidya, S. (2013), Contest functions: Theoretical foundations and issues in estimation, International Journal of Industrial Organization 31, 211-222.

Johnson, R.N., Libecap, G.D. (1982), Contracting problems and regulation: The case of the fishery, American Economic Review 72, 1005-1022.

Katz, A. (1988), Judicial decision making and litigation expenditure, International Review of Law and Economics 8, 127-143.

Konrad, K.A., Kovenock, D. (2009), The alliance formation puzzle and capacity constraints, Economics Letters 103, 84-86.

Kooreman, P., Schoonbeek, L. (1997), The specification of the probability functions in Tullock's rent-seeking contest, Economics Letters 56, 59-61.

Klumpp, T., Polborn, M.K. (2006), Primaries and the New Hampshire effect, Journal of Public Economics 90, 1073-1114.

Lu, J., Wang, Z. (2015), Axiomatizing multi-prize nested lottery contests: A complete and strict ranking perspective, Journal of Economic Behavior $\mathcal{G}^{3}$ Organization 116, 127-141.

Luce, R.D. (1959), Individual Choice Behavior, Wiley.

Manning, R., McMillan, J. (1979), Public intermediate goods, production possibilities, and international trade, Canadian Journal of Economics 12, 243-257. 
Margreiter, M., Sutter, M., Dittrich, D. (2005), Individual and collective choice and voting in common pool resource problem with heterogeneous actors, Environmental and Resource Economics 32, 241-271.

Menezes, F.M., Quiggin, J. (2010), Markets for influence, International Journal of Industrial Organization 28, 307-310.

Münster, J. (2009), Group contest success functions, Economic Theory 41, 345-357.

Noussair, C.N., van Soest, D., Stoop, J. (2015), Cooperation in a dynamic fishing game: A framed field experiment, American Economic Review 105, 408-413.

Ostrom, E., Gardner, R., Walker, J. (1994), Rules, Games, and CommonPool Resources, University of Michigan Press.

Ostrom, E. (2000), Reformulating the commons, Swiss Political Science Review 6, 29-52.

Pérez-Castrillo, D., Verdier, T. (1992), A general analysis of rent-seeking games, Public Choice 73, 335-350.

Rai, B.K., Sarin, R. (2009), Generalized contest success functions, Economic Theory 40, 139-149.

Rosen, S. (1986), Prizes and incentives in elimination tournaments, American Economic Review 76, 701-715. 
Shupp, R., Sheremeta, R.M., Schmidt, D., Walker, J. (2013), Resource allocation contests: Experimental evidence, Journal of Economic Psychology 39, 257-267.

Skaperdas, S. (1996), Contest success functions, Economic Theory 7, 283290.

Starrett, D.A. (1977), Measuring returns to scale in the aggregate, and the scale effect of public goods, Econometrica 45, 1439-1455.

Szidarovszky, F., Okuguchi, K. (1997), On the existence and uniqueness of pure Nash equilibrium in rent-seeking games, Games and Economic Behavior 18, 135-140.

Thomson, W. (1985), Axiomatic theory of bargaining with a variable population: A survey of recent results, Chapter 11 in Roth, A. (ed.), GameTheoretic Models of Bargaining, pp. 233-258.

Tullock, G. (1980), Efficient rent seeking. In: Buchanan, J., Tollison, R., Tullock, G. (Eds.), Toward a Theory of the Rent Seeking Society. Texas A\&M University Press, pp. 97-112.

Vesperoni, A. (2014), A contest success function for rankings, mimeo.

Walker, J., Gardner, R., Herr, A., Ostrom, E. (2000), Collective choice in the commons: Experimental results on proposed allocation rules and votes, Economic Journal 110, 212-234. 
Walker, J., Gardner, R., Ostrom, E. (1990), Rent dissipation in a limitedaccess common-pool resource: Experimental evidence, Journal of Environmental Economics and Management 19, 203-211. 